\title{
Cohabitee Left Home
}

National Cancer Institute

\section{Source}

National Cancer Institute. Cohabitee Left Home. NCI Thesaurus. Code C150729.

An indication that an individual who is or was living with another person left their shared home. 